\title{
Variations in diabetes remission rates after bariatric surgery in Spanish adults according to the use of different diagnostic criteria for diabetes
}

\author{
María R. Alhambra-Expósito*, María J. Molina-Puerta, María I. Prior-Sánchez, Gregorio Manzano-García,
} Alfonso Calañas-Continente and María A. Gálvez-Moreno

\begin{abstract}
Background: There are multiple criteria to define remission of type 2 diabetes (DM2) after bariatric surgery but there is not a specific one widely accepted. Our objectives were to compare diagnostic criteria for DM2 remission after bariatric surgery: Criteria from Spanish scientific associations (SEEN/SEEDO/SED) and from the American Diabetes Association (ADA). We also aim to analyse the degree of correlation between these sets of criteria.

Methods: Retrospective observational study in 127 patients undergoing bariatric surgery in a single centre (Hospital Universitario Reina Sofía, Córdoba, Spain) between January 2001 and December 2009. We analysed DM2 remission following bariatric surgery comparing DM2 diagnostic criteria approved by Spanish scientific associations and ADA criteria.

Results: In total, $62.2 \%$ of patients were women; mean age was 47.1 years. Following surgery, $52 \%$ achieved complete remission according to ADA criteria, and 63.8\% following the criteria approved by Spanish associations $(p=0.001) ; 18.9$ and $8.7 \%$, respectively, showed partial remission $(p=0.007)$, and 29.1 and $27.6 \%$ no remission, according to the criteria approved by each association ( $p=0.003$ ). There was good correlation between both sets of criteria (Rho $0.781 ; p<0.001)$.
\end{abstract}

Conclusions: In our series, using more stringent criteria for defining DM2 remission (ADA criteria) results in a lower rate of remission, although we found a a high degree of correlation between both sets of criteria.

Keywords: Bariatric surgery, Diabetes, Obesity, Gastric bypass

\section{Background}

Worldwide prevalence of type 2 diabetes (DM2) continues to increase simultaneously with obesity rates $[1,2]$. Over $60 \%$ of DM2 patients are obese [1], and this tandem is now a public health problem. Recent studies have shown that medical therapy for DM2 and comorbid obesity is not as successful as bariatric surgery, suggesting that modest weight loss and DM2 control is hard to achieve [3, 4]. American Diabetes Association (ADA) recommended for the first time in their 2010 edition of their standards of care [5] to consider bariatric surgery in the treatment of

\footnotetext{
* Correspondence: mralhambra@hotmail.com

UGC Endocrinología y Nutrición, Hospital Reina Sofía, Avenida Menéndez Pidal, s/n, 14004 Córdoba, Spain
}

DM2 patients with a body mass index (BMI) $\geq 35 \mathrm{~kg} / \mathrm{m}^{2}$. This indication is now widely accepted by leading international associations [6-9], particularly when DM2 or comorbidities are refractory to life style changes and pharmacological treatment.

The choice of criteria to define remission of DM2 after bariatric surgery is still widely debated. Some authors consider the withdrawal of medication to be the best criteria [10], while others suggest using various fasting plasma glucose (FPG) and glycated haemoglobin (HbA1c) cut-off points [11-13], or a combination of both [14-16]. After publication of the meta-analysis by Buchwald et al. in 2004, DM2 remission criteria 
recommended by these authors (HbA1c $<6 \%$ and FPG $100 \mathrm{mg} / \mathrm{dl}$ ) were the most used [17].

However, a consensus group from the ADA (Buse's consensus group [18]), consisting of experts in endocrinology, diabetes education, bariatric surgery and haematologyoncology, proposed in 2009 a new, far more stringent standard set of definition criteria based on biochemical (HbA1c and FPG levels) and clinical parameters (need for pharmacological treatment and duration of remission). In 2013, scientific associations in Spain published a position statement on metabolic surgery in patients with DM2 stating their set of criteria for define DM2 remission, which were similar to those approved by the ADA consensus group [19]. Considering the difficulty in establishing remission of DM2, Sánchez- Pernaute and Scopinaro have proposed using the ADA HbA1c cut-off point to diagnose DM2 [11, 20].

The aim of this study is to compare DM2 remission rates 5 years after bariatric surgery using the criteria approved by Spanish associations and ADA diagnostic criteria for DM2.

\section{Methods}

We conducted a retrospective observational study in 127 patients undergoing bariatric surgery in a single centre (Hospital Universitario Reina Sofía, Córdoba, Spain) between January 2001 and December 2009. All patients were diagnosed with DM2 and obesity (BMI $\geq 35 \mathrm{~kg} / \mathrm{m}^{2}$ ) before surgery, and had at least 3 years of follow-up with documentation of FPG, HbA1c levels, and body weight. Three types of bariatric surgery were performed: roux-en$\mathrm{Y}$ gastric bypass, sleeve gastrectomy and gastric band. The type of surgery was chosen depending on the patient's preoperative characteristics. Those undergoing bariatric surgery with a different technique were also excluded because of their low incidence. Patients who underwent a second bariatric surgery (including conversion, revisional and reversal procedures) were also excluded.

All procedures in studies involving human participants were performed in accordance with the ethical standards of the institutional review board of Hospital Universitario Reina Sofía and with the principles of the Declaration of Helsinki 2013. For this type of study formal consent was not required. This study was approved by the Ethics Committee of the Hospital Universitario Reina Sofía.

Demographic (age and sex), anthropometric (weight, height, BMI) and analytical (FPG and HbA1c) variables were collected during follow-up.

Remission of DM2 was defined using 2 different criteria: (1) those approved by Spanish scientific associations, based on HbA1c and FPG cut-off levels and need for diabetes medication, which classify their status as complete, prolonged or partial remission, improvement, or no remission, as shown in Table 1 [19]; and (2) ADA criteria, based on HbA1c levels and need for diabetes medication, which classify patients' status as complete or partial remission, optimal control, or no remission, as shown in Table 2 [20].

For the sake of statistical analysis, the complete and prolonged remission groups defined by the Spanish associations were included in the same group, given that prolonged remission according to the Spanish associations' criteria is included in the criteria for complete remission. Complete and partial remission and no remission criteria from both classification systems were compared. The improvement and optimal control criteria from the Spanish and ADA systems, respectively, were not compared separately, as these were both included in their respective no-remission classification.

Excess weight loss percentage (EWL\%) was calculated using the formula: [(initial weight- follow-up weight)/(initial weight - ideal weight)] X 100. Ideal weight was calculated for a BMI of $21 \mathrm{~kg} / \mathrm{m}^{2}$ in women, and $23 \mathrm{~kg} / \mathrm{m}^{2}$ in men. DM2 was diagnosed according to ADA criteria: FPG $>126 \mathrm{mg} / \mathrm{dl}, \mathrm{HbA} 1 \mathrm{c} \geq 6.5 \%$, random blood glucose $\geq 200 \mathrm{mg} / \mathrm{dl}$, or use of insulin or oral diabetes medication.

Glucose was measured in $\mathrm{mg} / \mathrm{dl}$, and $\mathrm{HbAlc}$ results are reported in NGSP/DCCT (\%) units (to 1 decimal point) [21].

\section{Statistical analysis}

In the descriptive analysis, qualitative variables in each category are expressed as absolute frequencies and percentage. Quantitative variables are expressed with their mean \pm standard deviation (SD) using the Shapiro-Wilk to test for normality. Non-parametric tests were used for variables with non-normal distribution, depending on the characteristics of the parameter. The chi-square analysis was used to test the association between qualitative variables. Student's t-test (normal distribution) or MannWhitney $U$ test (non-normal distribution) were used to compare means; ANOVA was used to compare means

Table 1 Post-bariatric surgery DM2 remission criteria approved by Spanish scientific associations [11, 12]

\begin{tabular}{ll}
\hline Complete remission & HbA1c $<6.5 \%$, FPG $<100 \mathrm{mg} / \mathrm{dl}[5.6 \mathrm{mmol} / \mathrm{l}]$ \\
& $\begin{array}{l}\text { and no need for diabetic medication for at } \\
\text { least } 1 \text { year of follow-up }\end{array}$ \\
Prolonged remission & Complete remission for more than 5 years. \\
Partial remission & $\mathrm{HbA} 1 \mathrm{c}<6.5 \%, \mathrm{FPG}: 100-125 \mathrm{mg} / \mathrm{dl}$ \\
& {$[5.6-6.9 \mathrm{mmol} / \mathrm{l}]$ and no need for diabetic } \\
& medication for at least 1 year of follow-up \\
Improvement & $\mathrm{HbA} 1 \mathrm{c}<7 \%$ with diabetic medication. \\
No remission & $\mathrm{HbA} 1 \mathrm{c} \geq 6.5 \%, \mathrm{FPG} \geq 126[6.9 \mathrm{~mm} / \mathrm{L}]$ \\
& and/or need for diabetic medication.
\end{tabular}

DM2 type 2 diabetes mellitus, FPG fasting plasma glucose, $\mathrm{HbA1c}$ glycated haemoglobin 
Table 2 Simplified DM2 diagnostic criteria based on $\mathrm{HbA} 1 \mathrm{c}$ proposed by ADA [13]

\begin{tabular}{ll}
\hline Complete remission & HbA1c $<5.7 \%$, with no need for diabetes \\
& medication for at least 1 year of follow-up \\
Partial remission & HbA1c $5.7-6.4 \%$, with no need for diabetes \\
& medication for at least 1 year of follow-up \\
Optimal control & HbA1c $<7 \%$ with or without diabetes \\
& medication. \\
No remission & HbA1c $>6.5 \%$ or active hypoglycaemic \\
& treatment
\end{tabular}

ADA American Diabetes Association, DM2 type 2 diabetes mellitus, HbA1c glycated haemoglobin

between non-dichotomous variables. Paired qualitative variables were compared using McNemar's test. Spearman's correlation coefficient was used as a measure of correlation between non-parametric variables. Statistical significance was set at $5 \%$, and statistical analysis was performed using SPSS version 15.0 for Windows.

\section{Results}

A total of 127 patients (62.2\% women) with DM2 were included in the study. Baseline and postoperative characteristics of patients are shown in Table 3. Mean age at the time of surgery was $47 \pm 8$ years; mean preoperative BMI was $50 \pm 7 \mathrm{~kg} / \mathrm{m}^{2}$, FPG was $134 \pm 53 \mathrm{mg} / \mathrm{dl}$ and HbA1c was $8 \pm 7 \%$. As shown in Table 3, patients presenting complete remission are younger, with lower postoperative $\mathrm{BMI}$, and lower pre- and postoperative FPG and HbA1c levels. These intra-group differences were found in both classifications (ANOVA test). Patients with no remission using both reclassification systems were more likely to have been on insulin (Fig. 1). Roux-en-Y gastric bypass was performed in $96 \%$ of patients, sleeve gastrectomy in 3\%, and gastric band in the remaining $1 \%$. Before surgery, 39 patients were in treatment with metformin, 6 with insulin, and 13 with other oral diabetes medication (ODM). Nineteen (19) patients were in treatment with a combination of metformin and insulin, and 14 with metformin and other ODM. Of the remaining patients, 36 were following a dietary and exercise programme, as DM2 had been diagnosed less than 6 months before surgery. After a mean followup of $5 \pm 2$ years, mean BMI, FPG and HbA1c were $37 \pm 6 \mathrm{~kg} / \mathrm{m}^{2}, 100 \pm 28 \mathrm{mg} / \mathrm{dl}$ and $6 \pm 1 \%$, respectively (Table 3). The difference between these and variables before and after surgery was statistically significant (paired samples t-tests; $p=0.001, p=0.007$ and $p=0.003$, respectively).

Following surgery, according to simplified HbA1c criteria, 52\% achieved remission, $18.9 \%$ improvement, and 29.1\% no remission. According to Spanish criteria, 63.8\% of patients presented with complete remission of DM2 (33.1\% with prolonged remission), 8.7\% achieved partial remission, and $27.6 \%$ no remission (of which $21.3 \%$ showed improvement of DM2). Statistically significant differences were observed between these reclassifications (McNemar's test; $p<0.001$ ). The reason behind this was that of 81 patients showing complete remission with the Spanish criteria, 59 achieved complete remission, 21 out of those 81 showed partial remission and 1 patient was classified as non remitter according to ADA criteria. Thirty-five (35) patients classified as non-remitters according to the Spanish reclassification were also considered non-remitters with the ADA criteria. Other 2 patients classified as non-remitters with ADA criteria were categorized in the group of complete remission (1) and partial remission (1) by Spanish reclassification.

Table 3 Patient characteristics and diabetes remission, grouped by different definition criteria

\begin{tabular}{|c|c|c|c|c|c|c|c|c|c|}
\hline & \multirow[t]{2}{*}{ Total } & \multicolumn{4}{|c|}{ SEEN/SEEDO/SED } & \multicolumn{4}{|l|}{$\mathrm{ADA}$} \\
\hline & & Complete & Partial & No Remission & $P$ value* & Complete & Partial & No Remission & $P$ value* \\
\hline No. Patients & 127 & 81 & 11 & 35 & - & 66 & 24 & 37 & - \\
\hline Age (years) & $47.1 \pm 8.5$ & $45.1 \pm 8.8$ & $48.8 \pm 6.3$ & $51.2 \pm 6.8$ & 0.001 & $45.1 \pm 8.1$ & $45.6 \pm 8.8$ & $51.5 \pm 6.8$ & 0.001 \\
\hline Women & 62 & 55 & 1 & 23 & 0.241 & 41 & 13 & 25 & 0.142 \\
\hline Pre BMI $\left(\mathrm{kg} / \mathrm{m}^{2}\right)$ & $50.9 \pm 7.6$ & $51.9 \pm 8.1$ & $49.9 \pm 2.7$ & $49.0 \pm 6.9$ & 0.056 & $51.5 \pm 7.6$ & $51.9 \pm 8.2$ & $49.2 \pm 6.8$ & 0.319 \\
\hline Post BMI $\left(\mathrm{kg} / \mathrm{m}^{2}\right)$ & $37.2 \pm 6.1$ & $36.5 \pm 6.4$ & $38.4 \pm 3.5$ & $38.5 \pm 6.1$ & 0.046 & $35.8 \pm 5.4$ & $38.9 \pm 7.6$ & $38.5 \pm 5.9$ & 0.030 \\
\hline Pre FPG $(\mathrm{mg} / \mathrm{dl})$ & $134.8 \pm 53.7$ & $115.7 \pm 37.9$ & $159.2 \pm 61.4$ & $155.8 \pm 63.1$ & 0.001 & $115.3 \pm 34.5$ & $150.7 \pm 70.8$ & $154.6 \pm 16.5$ & 0.000 \\
\hline Post FPG (mg/dl) & $100.0 \pm 28.5$ & $85.1 \pm 121.8$ & $111.6 \pm 16.1$ & $126.0 \pm 34.1$ & 0.002 & $87.7 \pm 15.0$ & $87.5 \pm 12.8$ & $126.6 \pm 33.1$ & 0.003 \\
\hline Pre HbA1c (\%) & $8.0 \pm 7.6$ & $7.6 \pm 1.9$ & $7.9 \pm 1.6$ & $9.0 \pm 2.0$ & 0.000 & $7.6 \pm 1.9$ & $7.8 \pm 16$ & $9.0 \pm 2.0$ & 0.000 \\
\hline Post HbA1c (\%) & $5.8 \pm 0.8$ & $5.5 \pm 0.4$ & $5.5 \pm 0.4$ & $6.7 \pm 0.9$ & 0.018 & $5.3 \pm 0.3$ & $6.0 \pm 0.2$ & $6.8 \pm 0.9$ & 0.001 \\
\hline EWL\% & $51.0 \pm 18.3$ & $55.4 \pm 17.5$ & $40.9 \pm 12.3$ & $43.9 \pm 18.7$ & 0.573 & $54.8 \pm 16.8$ & $50.9 \pm 20.1$ & $44.2 \pm 18.3$ & 0.001 \\
\hline
\end{tabular}

The bold numbers remark the differences

*Intra-group differences in both classifications: Anova test

ADA American Diabetes Association. EWL\% excess weight loss percentage, Post BMI postoperative body mass index, Pre BMI: preoperative body mass index, Post FPG postoperative fasting plasma glucose, Pre FPG preoperative fasting plasma glucose, Post HbA1c postoperative glycated haemoglobin, Pre HbA1c preoperative glycated haemoglobin, SEEN /SEEDO /SED Sociedad Española de Endocrinología y Nutrición / Sociedad Española para el Estudio de la Obesidad / Sociedad Española de Diabetes 


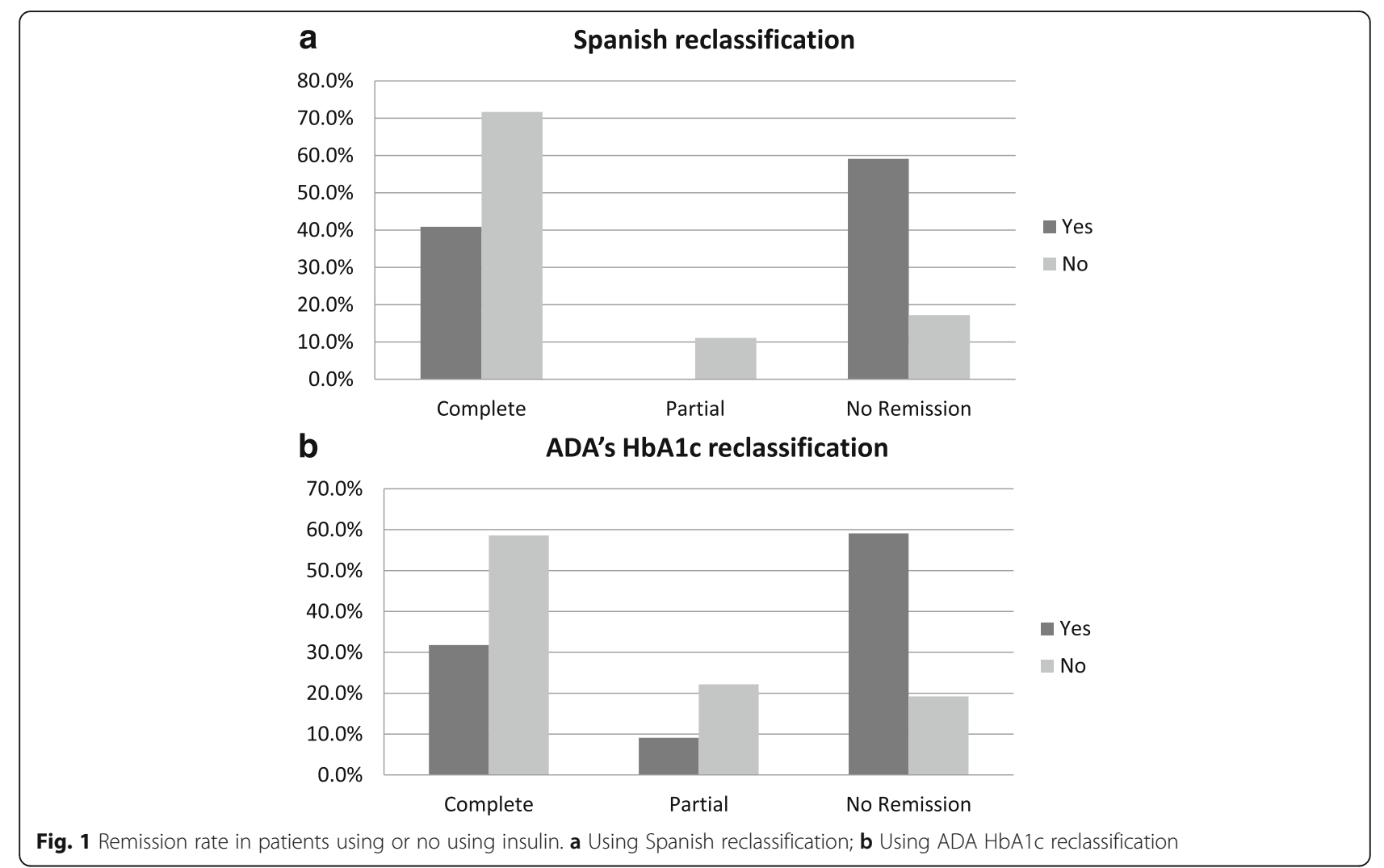

There is a good correlation between the reclassification systems (Spearman's rho $=0.781, p<0.001$ ). Fifty-nine (59) patients showed complete remission, 3 partial remission, and 35 no remission under both sets of criteria (Table 4).

\section{Discussion}

There is a certain amount of controversy regarding the best criteria to define diabetes remission following bariatric surgery. EWL\% is known to be a predictive factor of DM2 remission: the higher the EWL\%, the greater the likelihood of remission [22]. This was found to be true in our series. Between the partial remission and no remission groups according to the Spanish criteria, although there were differences, they were not statistically significant. Remission is also associated with age and the degree of DM2 control. Our study has shown that complete DM2 remission is more common in young patients and in those with better-controlled mean HbA1c and FPG levels. Our findings also show that more stringent criteria for defining DM2 remission results in a lower rate of complete remission categorised as total remission. Instead, they would be categorised as partial remission (63.8\% with complete remission under Spanish criteria vs. $52 \%$ complete remissions following the ADA's more stringent criteria $[\mathrm{HbA} 1 \mathrm{c}<5.7 \%])$. Some authors consider DM2 to be in remission purely on the basis of clinical criteria (no need for diabetes medication) or a single analytical finding: FPG or HbA1c [2, 23]. In the meta-analysis performed by Buchwald et al. [24], remission rates varied considerably (54.9-95.1\%), depending on the type of surgery or definition criteria used (FPG $<100 \mathrm{mg} / \mathrm{dl}$ or HbA1c $<6 \%$ ). Other studies and systematic reviews with high remission rates also used

Table 4 Postoperative diagnostic reclassification

\begin{tabular}{|c|c|c|c|c|c|}
\hline & & \multicolumn{3}{|l|}{ Spanish reclassification } & \multirow[t]{2}{*}{ Total } \\
\hline & & Complete remission & Partial remission & No remission & \\
\hline \multirow[t]{3}{*}{ ADA HbA1c reclassification } & Complete remission & 59 & 7 & 0 & 66 \\
\hline & Partial remission & 21 & 3 & 0 & 24 \\
\hline & No remission & 1 & 1 & 35 & 37 \\
\hline Total & & 81 & 11 & 35 & 127 \\
\hline
\end{tabular}


less demanding criteria [2, 23] and relatively short (1 to 2 years) follow-up periods. Different approaches to define remission have also led to false expectations with regard to the true percentage of patients achieving long-term diabetes remission. For example in the SOS study the 2-year DM2 remission rate of $72 \%$ declined to a $36 \%$ remission rate after 10 years [14]. In our series, after a mean followup of 64 months, $52 \%$ of patients achieved complete remission under ADA criteria, i.e. HbA1c $<5.7 \%$ and no need for diabetes medication. This is consistent with other studies [25-27] reporting remission rates of 40.6, 43.6 and $50 \%$. Specifically, Ramos-Levi [27] et al., in a retrospective cohort of 110 patients, compared DM2 remission rates based on the same definition criteria used in our study. There were some differences between these studies; though mean BMI in their patients was lower than in our study $(43.6 \pm 5.5$ vs $50.9 \pm 7.6 \mathrm{~kg} / \mathrm{m} 2)$ and the percentage of patients on insulin in their study was higher than in our study (44.5\% vs $19.7 \%)$. They found no statistically significant differences between remission rates $(50 \%$ of total remission using both the Spanish and ADA criteria). However, follow-up was limited to 18 months. In our 5year follow-up study, we found that remission rates did differ depending on the definition criteria used. This is probably due to the fact that our follow-up period is one of the longest of all studies in DM2 remission. This begs the question whether these remission rates can be sustained over a long-term follow-up of 10 years or more. ADA remission criteria are the most stringent and the most widely used. To confirm DM2 remission, therefore, these same criteria should be applied and updated according to established standards.

One limitation of our study lies in the fact that retrospective cohorts are more susceptible to bias, such as loss to follow-up. In addition, some relatively important data, such as time from onset of diabetes to bariatric surgery, were missing. Another possible limitation is that we did not take into consideration differences between surgical techniques, because very few sleeve gastrectomies were performed during the study period due to the preferences and experience of the surgical team. Into the bargain we cannot know whether patients with new diabetes drugs such as SGLT-2 inhibitors or GLP-1 analogues would have similar or unrelated remission rates, because during the years in which these patients (20012009) were included, these drugs were not available in Spain.

\section{Conclusion}

In conclusion, we believe that strict criteria based on those established by the ADA with the addition of the Spanish prolonged remission criteria should be used to determine true remission of diabetes following bariatric surgery. Further studies in larger cohorts with longer follow-up periods are needed to conclusively show the best criteria for defining post-bariatric surgery diabetes remission.

\section{Abbreviations \\ ADA: American Diabetes Association; BMl: Body mass index; DM2: Type 2 diabetes; EWL\%: Excess weight loss percentage; FPG: Fasting plasma glucose; HbA1c: Glycated haemoglobin; SD: Standard deviation; SEEN/SEEDO/ SED: Sociedad Española de Endocrinología /Sociedad Española para el estudio de la obesidad / Sociedad Española de Diabetes.}

\section{Acknowledgements}

Not applicable.

Funding

Not applicable.

\section{Availability of data and materials}

The datasets used and/or analysed during the current study are available from the corresponding author on reasonable request.

\section{Authors' contributions}

MRAE participated in the design of the study, performed the statistical analysis and wrote the manuscript. MJMP conceived the study, participated in its design and coordination and helped to draft the manuscript. MIPS also helped to draft the manuscript, and participated in its design. GMG and ACC participated in its design. MAGM supervised all the work; also been involved in drafting the manuscript or revising it critically for important intellectual content and she gave the final approval of the version to be published. All authors read and approved the final manuscript.

\section{Ethical approval and consent to publish}

All procedures in studies involving human participants were performed in accordance with the ethical standards of the institutional review board of Hospital Universitario Reina Sofía and with the principles of the Declaration of Helsinki 2013. For this type of study formal consent was not required (Artículo 27,5 de la Ley 30/1992, de 26 de noviembre del Régimen Jurídico de las Administraciones Públicas y del Procedimiento Administrativo Común"). This study was approved by the Ethics Committee of the Hospital Universitario Reina Sofía.

Consent for publication

Not applicable.

\section{Competing interests}

The authors declare they have no competing interests.

\section{Publisher's Note}

Springer Nature remains neutral with regard to jurisdictional claims in published maps and institutional affiliations.

Received: 6 March 2017 Accepted: 2 August 2017

Published online: 15 August 2017

\section{References}

1. Whiting DR, Guariguata L, Weil C, Shaw J. IDF diabetes atlas: global estimates of the prevalence of diabetes for 2011 and 2013. Diabetes Res ClinPract. 2011;94(3):311-21.

2. Dixon JB, le Roux CW, Rubino F, Zimmet P. Bariatric surgery for type 2 diabetes. Lancet. 2012:379(9833):2300-11.

3. Mingrone G, Panunzi S, De Gaetano A, Guidone C, Laconelli A, Leccesi L, et al. Bariatric surgery versus conventional medical therapy for type 2 diabetes. N Engl J Med. 2012;366(17):1577-85.

4. Schauer PR, Kashyap SR, Wolski K, Brethauer SA, Kirwa JP, Pothier CE, et al. Bariatric surgery versus intensive medical therapy in obese patients with diabetes. N Engl J Med. 2012;366(17):1567-76.

5. American Diabetes Association. Standards of medical care in diabetes 2010. Diabetes Care. 2010;33:S11-61. 
6. Dixon JB, Zimmet P, Alberti KG, Mbanya JC, RUbino F. Bariatric surgery for diabetes: the International Diabetes Federation takes a position. J Diabetes. 2011;3:261-4.

7. American Diabetes Association. Standards of medical care in diabetes 2013 (Position Statement). Diabetes Care. 2013;36(Suppl 1):S11-66.

8. National Institute for Health and Clinical Excellence (NICE). Obesity: guidance on the prevention, identification, assessment and management of overweight and obesity in adults and children; 2006.

9. Kasama K, Mui W, Lee WJ, Lakdawala M, Naitoh T, Seki Y, et al. International Federation for the Surgery of Obesity and Metabolic Disorders/Asian Pacific Chapter (IFSO-APC) consensus statements 2011. Obes Surg. 2012;22:677-84.

10. Dolan $\mathrm{K}$, Bryant R, Fielding $\mathrm{G}$. Treating diabetes in the morbidly obese by laparoscopic gastric banding. Obes Surg. 2003;13:439-43.

11. Sánchez-Pernaute A, Herrera MA, Pérez-Aguirre ME, Talavera P, Cabrerizo L, Matía P, et al. Single anastomosis duodeno-ileal bypass with sleeve gastrectomy (SADI-S). One to three-year follow-up. Obes Surg. 2010;20:1720-6.

12. Scopinaro N, Adami GF, Papadia FS, Camerini G, Carlini F, Briatore L, et al. The effects of biliopancreatic diversion on type 2 diabetes mellitus in patients with mild obesity (BMI 30-35 kg/m2) and simple overweight (BMI 25-30 kg/m2): a prospective controlled study. Obes Surg. 2011;21:880-8.

13. Sánchez-Pernaute A, Rubio MA, Pérez Aguirre E, Barabash A, Cabrerizo L, Torres A. Single-anastomosis duodenoileal bypass with sleeve gastrectomy: metabolic improvement and weight loss in first 100 patients. Surg Obes Relat Dis. 2013;9(5):731-5.

14. Sjöström L, Lindroos AK, Peltonen M, Torgerson J, Bouchard C, Carlsson B, et al. Lifestyle, diabetes, and cardiovascular risk factors 10 years after bariatric surgery. N Engl J Med. 2004;351:2683-93.

15. Lee WJ, Chong K, Ser KH, et al. Gastric bypass vs sleeve gastrectomy for type 2 diabetes mellitus: a randomized controlled trial. Arch Surg. 2011;146: $143-8$.

16. Hamza N, Abbas MH, Darwish A, Shafeekb Z, Newa J, Ammori BJ. Predictors of remission of type 2 diabetes mellitus after laparoscopic gastric banding and bypass. Surg Obes Relat Dis. 2011;7:691-6.

17. Buchwald H, Avidor Y, Braunwald E, Jensen MD, Pories W. Fahrabach et al. Bariatric surgery: a systematic review and meta-analysis. JAM. 2004;292(14): 1724-37.

18. Buse JB, Caprio S, Cefalu WT, Ceriello A, Del Prado S, Inzucchi SE, et al. How do we define cure of diabetes? Diabetes Care. 2009;32:2133-5.

19. Rubio MA, Monereo S, Lecube A, Resa J, Masdevall C, de la Cruz VF, et al. Joint position statement of the SEEN-SECO-SEEDO-SED societies on metabolic surgery for type 2 diabetes mellitus. Endocrinol Nutr. 2013;60(10): $547-8$.

20. American Diabetes Association. Diagnosis and classification of diabetes mellitus. Standard of medical care of diabetes -2017. Diabetes Care. 2017; 40(Suppl 1):S1-2.

21. Little RR, Sacksb DB. HbA1c: how do we measure it and what does it mean? Curr Opin Endocrinol Diabetes Obes. 2009;16:113-8.

22. Brethauer SA, Aminian A, Romero-Talamás H, Batayyah E, Mackey J, Kennedy $L$, et al. Can diabetes be surgically cured?: long-term metabolic effects of bariatric surgery in obese patients with type 2 diabetes mellitus. Ann Surg. 2013;258(4):628-37.

23. Adams TD, Pendleton RC, Strong MB, Kilotkin RL, Walker JM, Litwin SE, et al. Health outcomes of gastric bypass patients compared to nonsurgical, non intervened severely obese. Obesity (Silver Spring). 2010;18:121-30.

24. Buchwald H, Estok R, Fahrbach K, Banel D, Jensen MD, Pories WJ, et al. Weight and type 2 diabetes after bariatric surgery: systematic review and meta-analysis. Am J Med. 2009;122:248-56. e5

25. Pournaras DJ, Aasheim ET, Søvik TT, Andrews R, Mohon D, Welbourn R, et al. Effect of the definition of type II diabetes remission in the evaluation of bariatric surgery for metabolic disorders. Br J Surg. 2012;99:100-3.

26. Mas-Lorenzo A, Benaiges D, Flores-Le-Roux JA, Pedro-Botet J, Ramon JM, Parri A, et al. Impact of different criteria on type 2 diabetes remission rate after bariatric surgery. Obes Surg. 2014;24(11):1881-7. doi:10.1007/s11695014-1282-2.

27. Ramos-Levi AM, Cabrerizo L, Matía P, Sánchez-Pernaute A, Torres AJ, Rubio MA. Which criteria should be used to define type 2 diabetes remission after bariatric surgery? BMC Surg. 2013;13:8.

\section{Submit your next manuscript to BioMed Central and we will help you at every step:}

- We accept pre-submission inquiries

- Our selector tool helps you to find the most relevant journal

- We provide round the clock customer support

- Convenient online submission

- Thorough peer review

- Inclusion in PubMed and all major indexing services

- Maximum visibility for your research

Submit your manuscript at www.biomedcentral.com/submit
Biomed Central 